\title{
Relationship between Plasma Vascular Endothelial Growth Factor (VEGF) and Ovarian Cancer Staging
}

\author{
Erma Wahyuni ${ }^{1}$, Herman Hariman ${ }^{1}$, Deri Edianto ${ }^{2}$ \\ ${ }^{1}$ Department of Clinical Pathology, Faculty of Medicine, Universitas Sumatera Utara / Haji Adam Malik \\ General Hospital, Medan, North Sumatera \\ ${ }^{2}$ Department of Obstetrics and Gynecology, Faculty of Medicine, Universitas Sumatera Utara / Haji Adam \\ Malik General Hospital, Medan, North Sumatera \\ Corresponding Author: Erma Wahyuni
}

\begin{abstract}
Ovarian cancer is the 8 th most common cancer that occurs in most women. In a 2018 survey by Global Cancer Statistics in 185 countries of all cancer cases, $3.4 \%$ were caused by ovarian cancer. Vascular endothelial growth factor is a multifunctional cytokine that stimulates angiogenesis and increases microvascular permeability by binding to receptors located in endothelial cells in blood vessels. Immature platelet fraction (\% IPF) is a modern parameter that measures young platelets and reticulation in peripheral blood. The purpose of this study was to look at differences in plasma VEGF and IPF levels between ovarian cancer sufferers and staging of ovarian cancer. This type of research is a cross sectional observational study of VEGF and Ovarian Cancer stage. A total of 18 people with ovarian cancer were sampled before surgery and after surgery an anatomy pathology examination was performed to assess early stage and advanced cancer staging. From 18 patients with ovarian cancer obtained from the early stage ovarian cancer group and advanced stage group. Obtained a median age of 50 (42-63), whereas in the advanced stage group a median age of 51 (19-68) was obtained. There is a significant difference between VEGF levels in early and advanced stage ovarian cancer with a value of $\mathrm{p}=0,000$. Using the Spearman Correlation test to assess the correlation between tumor size and VEGF levels, $p$ values $<0.001$ with $\mathrm{r}=0.742$ were obtained. The conclusion of this research are advanced stage
\end{abstract}

ovarian cancer VEGF is significantly higher $\mathrm{P}=$ 0.001 compared to early stage.

Keywords: VEGF, Ovarian Cancer

\section{BACKGROUND}

Ovarian cancer is the eighth most common cancer that occurs in most women and accounts for about $4 \%$ of all cancers in women. This cancer has a high morbidity and mortality rate among other cancers of the reproductive system. The ovarian cancer mortality rate is still high despite the discovery of new chemotherapy drugs. The main reason is the low success in diagnosing ovarian cancer at an early stage, because most of the patients die at an advanced stage, conversely if ovarian cancer is detected early about $90 \%$ of those with well-differentiated ovarian malignancies survive better. The lack of reliable tumor markers to predict clinical features and response to treatment is also a major factor. ${ }^{2}$

Vascular endothelial growth factor (VEGF) is a multifunctional cytokine that stimulates angiogenesis and increases microvascular permeability through binding to receptors located on blood vessel endothelial cells. Although VEGF is expressed in some tumors and hypoxic tissues, its receptors are expressed primarily by endothelial cells, where VEGF plays an important role in the formation of new blood vessels (neovascularization) and 
nourishes highly metabolic tumor cells and provides access to host blood vessels. ${ }^{3}$ This study aims at assessing the correlation of serum VEGF levels in predicting degree of severity in patients with ovarian cancer.

\section{RESEARCH METHOD}

This study is an observational cross sectional study which performed at Haji Adam Malik General Hospital Medan with permission from Research Ethics Committee of the Faculty of Medicine, Universitas Sumatera Utara-RSHAM. Subjects were recruited from July to November 2019 consecutively. The inclusion criteria were patients who were confirmed as ovarian cancer and underwent surgical excision of the tumor and then histopathological examination was performed. Serum VEGF levels were checked using the ELISA method. The results of the examination of serum VEGF levels and tumor staging were then calculated statistically.

\section{RESULT AND DISCUSSION}

A total of 18 patients with ovarian cancer were included in this study. Characteristics of research subjects can be seen in Table 1. All research subjects are female. The research subjects were then grouped into 2 groups, namely the early stage ovarian cancer group and the advanced ovarian cancer group.

Table 1. Characteristics of Research Subjects

\begin{tabular}{|c|c|c|c|c|c|c|}
\hline \multirow[t]{2}{*}{ Variable } & \multirow{2}{*}{$\begin{array}{l}\text { Value } \\
(\%)\end{array}$} & \multicolumn{2}{|c|}{ Early Stage $(n=9)$} & \multicolumn{2}{|c|}{ Advanced Stage (n=9) } & \multirow[t]{2}{*}{ P Value } \\
\hline & & Mean (SD) & Median(min-max) & Mean (SD) & Median(min-max) & \\
\hline Age & & $51,44(7,35)$ & $50(42-63)$ & $48,88(13,11)$ & $51(19-68)$ & $0,965^{*}$ \\
\hline Age at first menstruation & & $9,33(0,50)$ & $9(9-10)$ & $9,77(0,83)$ & $10(9-11)$ & $0,234 *$ \\
\hline $\begin{array}{l}\text { The age at which the patient } \\
\text { was married }\end{array}$ & & $21,00(3,04)$ & $20,00(16,00-25,00)$ & $19,33(2,23)$ & $19,00(17,00-24,00)$ & $0,161^{*}$ \\
\hline \multicolumn{7}{|l|}{ Menopausal status } \\
\hline Yes & $12(66.7)$ & & & & & \\
\hline Not yet & $6(33.3)$ & & & & & \\
\hline \multicolumn{7}{|l|}{ Contraceptive use status } \\
\hline There is no & $3(16.7)$ & & & & & \\
\hline Pill & $10(55.6)$ & & & & & \\
\hline Spiral & $2(11.1)$ & & & & & \\
\hline Injection & $3(16.7)$ & & & & & \\
\hline \multicolumn{7}{|l|}{ Level of education } \\
\hline Primary School & $9(50)$ & & & & & \\
\hline Junior School & $5(27.8)$ & & & & & \\
\hline Senior School & $3(16.7)$ & & & & & \\
\hline College & $1(5.6)$ & & & & & \\
\hline
\end{tabular}

In this study, blood was drawn to assess VEGF and IPF levels. From the examination of VEGF levels, the average value of VEGF levels for all samples was 185.27 with a standard deviation of 141.96 , and a median of 111.59 with the lowest VEGF level of 32.81 and the highest VEGF level of 456.81. From the radiological examination and anatomical pathology, the stage for ovarian $\mathrm{Ca}$ was concluded in the patient. Ovarian Ca patients with stage I a as many as 1 patient $(5.6 \%)$, stage IIIa2 as many as 1 patient $(5.6 \%)$, stage III b as many as 3 patients $(16.7 \%)$, p stadium III c as many as 5 patients $(27.8 \%)$, stage I c was
1 patient, and stage II b was 7 patients $(38.9 \%)$.

Table 2. Initial measurement data VEGF levels and ovarian cancer stage

\begin{tabular}{|l|l|l|l|}
\hline Variable & $\begin{array}{l}\text { Nilai } \\
(\mathbf{\%}) \\
(\mathbf{n = 1 8})\end{array}$ & Mean (SD) & $\begin{array}{l}\text { Median } \\
(\mathbf{m i n}-\mathbf{m a x})\end{array}$ \\
\hline Kadar VEGF & & $185,27(141,96)$ & $\begin{array}{l}111,59 \\
(32,81-456,81)\end{array}$ \\
\hline $\begin{array}{l}\text { Stadium Ca } \\
\text { Ovarium }\end{array}$ & & & \\
\hline Ia & $1(5.6)$ & & \\
\hline IIIa2 & $1(5,6)$ & & \\
\hline IIIb & $3(16,7)$ & & \\
\hline IIIc & $5(27,8)$ & & \\
\hline Ic & $1(5,6)$ & & \\
\hline IIb & $7(38,9)$ & & \\
\hline
\end{tabular}


The stage of ovarian cancer is classified into 2 groups, namely stage 1 and 2 which are grouped into early stages and stages 3 and 4 are grouped into advanced stages. By using the Mann Whitney U test, a significant difference was found between VEGF levels in early stage ovarian $\mathrm{Ca}$ and VEGF levels in advanced ovarian Ca with $\mathrm{p}$ value $<0.001$ Table 3 .

Table 3. Median of VEGF in early and advanced ovarian cancer $(\mathbf{n}=9)$

\begin{tabular}{|l|l|l|l|l|}
\hline Test & Median & Lowest & Highest & p \\
\hline VEGF Early Stage & 63,75 & 32,81 & 113,18 & $<0,001$ \\
\cline { 1 - 1 } $\begin{array}{l}\text { VEGF Advanced } \\
\text { Stadium }\end{array}$ & 321,6 & 110 & 456,81 & $*$ \\
\hline
\end{tabular}

\section{DISCUSSION}

In this study, it was found that most $\mathrm{Ca}$ ovarian patients were elderly, the average age of early stage $\mathrm{Ca}$ ovarian patients was 51.44 (7.35) years and advanced ovarian $\mathrm{Ca}$ patients were 48.88 (13.11) years old. Ovarian $\mathrm{Ca}$ is an agerelated disease, and is considered primarily a postmenopausal disease. This increased incidence of cancer is more pronounced in women over the age of 65 . According to previous studies, the average age at diagnosis is 50-79 years. The relationship between age and ovarian cancer outcome is uncertain. Although many investigators have shown that younger age of ovarian cancer is associated with improved outcome, the other 6 ages mentioned are not an independent prognostic factor. Older age in this disease is associated with more advanced disease and lower survival level. Older women were treated less aggressively in contrast to younger ovarian cancer patients, and, thus, survival was lower in this group. Age over 64 years is one predictor of death in people with ovarian cancer.

In this study, the age at first menstruation in the early stage $\mathrm{Ca}$ ovarian group was $9.33(0.50)$ years, while the age at first menstruation in the advanced stage $\mathrm{Ca}$ ovarian group was 9.77 (0.83) years. In many studies, researchers have shown an inverse relationship between the ovulation cycle and ovarian cancer risk. The results of the case-control study showed that, in women who had not had an ovulation cycle for 8.7 years, the risk of ovarian cancer was reduced by 4 times $(\mathrm{OR}=0.23$ [0.10-0.50]). This finding supports the theory. "Continuous ovulation". Based on this theory, incessant ovulation can contribute to the onset of ovarian cancer by damaging the ovarian epithelium; therefore, any factor that contributes to a reduction in ovulation can have a protective effect against ovarian cancer. Although the results of some studies show an association between early onset of menarche and risk of ovarian cancer, other researchers report that age of menarche and menopause has no effect on ovarian cancer risk.

In this study, it was found that most of Ca ovarian sufferers used hormonal birth control, 10 (55.6\%) people and $3(16.7 \%)$ people used injection contraceptives. The results of most studies indicate that the use of oral contraceptive methods is associated with a reduced risk of all types of ovarian cancer. The results of a case-control study in Canada showed that the use of hormonal contraceptive pills was associated with a significant reduction in all histological types of epithelial ovarian cancer, except for mucin tumors. According to the findings of this study, or for each year of use these pills were 0.89 [0.85-0.93] for non-mucinous tumors and 0.98 [0.93-1.04] for mucinous tumors. 53 The results of the case-control study show that the oral contraceptive pill (OCP) reduces the risk of fatal and advanced ovarian cancer compared with less advanced cases. Royar et al. stated that, each year, use of the combined oral contraceptive pill reduced the risk of ovarian cancer by $7 \%(\mathrm{OR}=0.93$ [0.90$0.96]$ ), and this reduction was more pronounced during first use at less than 25 years of age. Although there is an inverse relationship between the time using hormonal contraceptive pills, the age at which they are used, and the risk of ovarian cancer, the duration of consumption is more important. This risk reduction can last up to 10-15 years after pill discontinuation; 
however the protective effect of oral contraceptives has not been proven in many studies. 50 In case-control studies, no association was found between use of contraceptive methods (except for tube ligation) and risk of ovarian cancer.

In this study, it was found that VEGF levels in early-stage ovarian $\mathrm{Ca}$ patients were significantly different from VEGF levels in late-stage ovarian $\mathrm{Ca}$ patients, where the median VEGF level in early-stage ovarian $\mathrm{Ca}$ patients was 63.75 (32.81-113.18) whereas The median value of VEGF levels in patients with advanced ovarian Ca was 321.6 (110-456.81) with $\mathrm{p}$ value $<0.001$. This is also supported by research conducted by Cheng et al (2013) who conducted a study on VEGF levels for diagnostic and prognostic cases of ovarian $\mathrm{Ca}$ in China. The results in this study found that serum VEGF levels were correlated with FIGO stage, lymph node metastasis, tumor resectability, and patient survival with a $\mathrm{p}$ value <0.01. Another study conducted by Ranjbar et al (2015) showed that there were differences. Significant between VEGF levels in Ovarian $\mathrm{Ca}$ patients compared with normal people with a $\mathrm{p}$ value $=0.02$. Other supporting research regarding the VEGF and VEGF receptor levels associated with prognostic factors from $\mathrm{Ca}$ ovarian was conducted by Skirnisdottir, 2016. The results of this study are VEGF level is an independent risk factor for prognostic determination of ovarian $\mathrm{Ca}$ with the HR result in multivariate analysis of 1.404 .

VEGF was first shown to induce lymphangiogenesis and promote metastasis in animal studies, and is also expressed in a variety of adult human tissues including the heart, placenta, muscle, ovaries, and small intestine. Previous studies have shown that the VEGF-C / VEGFR3 signaling system is considered the most efficient pathway in regulating lymphangiogenesis. VEGF-C secreted by tumor cells can specifically act on the VEGFR-3 receptor on the surface of lymphatic endothelial cells, thereby activating the signaling system for tumor lymphangiogenesis. Clinicopathological correlation has shown that there is a strong correlation between VEGF-C / VEGFR3 signaling and lymph node metastases in various human cancers. Nakazato $\mathrm{T}$, et al. reported that VEGF-C expression in oral squamous cell carcinoma triggers lymphangogenesis, which may result in a high risk for cervical lymph node metastases. Schietroma $\mathrm{C}$ et al, showed that VEGF-C positive lymphatic density was increased around malignant melanoma and was associated with cell invasion tumors of the lymph nodes. Recent studies identify VEGF-C as a prognostic factor for poor prognosis in gastric adenocarcinoma, cholangiocarcinoma, breast cancer, and lung cancer.

Neoplastic angiogenesis and lymphangiogenesis are essential for the growth of tumor tissue at the primary site and metastases. This implies that detection of weed and lymphangiogenic factors may indicate the presence of a malignant tumor at an early stage. Very few data have focused on lymphangiogenesis in ovarian cancer. However, Sinn BV, et al, demonstrated that VEGF-C mRNA is associated with aggressive tumor behavior in ovarian cancer. Although, an increase in VEGF-C mRNA was observed, the relationship between serum VEGF-C levels and tumor behavior has not been determined by in vivo quantitative methods.

\section{CONCLUSION}

The conclusion of this research are advanced stage ovarian cancer VEGF is significantly higher $\mathrm{P}=0.001$ compared to early stage.

\section{Acknowledgement: None}

Conflict of Interest: None

Source of Funding: None

Ethical Approval: Approved 


\section{REFERENCES}

1. Arora N, Talhouk A, Mcalpine JN, et al. Long-term mortality among women with epithelial ovarian cancer: a populationbased study in British Columbia, Canada. BMC Cancer 2018; 18: 1-9.

2. Baker H. Incessant Ovulation - A Factor In Ovarian Neoplasia ? Lancet 1969; 1966.

3. Bamberger ES, Perrett CW. Angiogenesis in epithelian ovarian cancer. Int J Pathol 2002; 455: 348-359.

4. Chornokura G, Amankwaha EK, Schildkrautc JM, et al. Global ovarian cancer health disparities. Gynecol Oncol 2014; 129: 258-264.

5. Chan J, Urban R, Cheung M, et al. Ovarian cancer in younger vs older women: a population-based analysis Clinical Studies. Br J Cancer 2006; 95: 1314-1320.

6. Cheng D, Liang B, Li Y. Serum Vascular Endothelial Growth Factor ( VEGF-C) as a Diagnostic and Prognostic Marker in Patients with Ovarian Cancer. plosone 2013; 8: $1-6$.

7. Fujita M, Ase TORUT, Akugawa YOK, et al. Smoking, Earlier Menarche and Low Parity as Indepen- dent Risk Factors for Gynecologic Cancers in Japanese : A CaseControl Study. 2008; 6: 297-307.

8. Harabuchi I, Miyake H, Casagrande JT, et al. Reproductive , Genetic , And Dietary Risk Factors For Ovarian Cancer. Am J Epidemiol Adv Access 1988; 128: 771-777.

9. Joukov V, Pajusola K, Kaipainen A, et al. A novel vascular endothelial growth factor, VEGF-C, is a ligand for the Flt4 ( VEGFR3 ) and KDR ( VEGFR-2 ) receptor tyrosine kinases. embo J 1996; 15: 290-298.

10. Kim SJ, Rosen B, Fan I, et al. Epidemiologic factors that predict long-term survival following a diagnosis of epithelial ovarian cancer. Br J Cancer 2017; 116: $964-$ 971.

11. Li R, Stewart DJ, von Schroeder HP, et al. Effect of cell-based VEGF gene therapy on healing of a segmental bone defect. J Orthop Res 2009; 27: 8-14.

12. Massi D, Susini T, Savino L, et al. Epithelial ovarian tumors in the reproductive age group: age is not an independent prognostic factor. Cancer 1996; 77: 1131-1136.

13. Momenimovahed Z, Tiznobaik A, Taheri S, et al. Ovarian cancer in the world: epidemiology and risk factors. 2019; $287-$ 299.

14. Ørskov M, Iachina M, Guldberg R, et al. Predictors of mortality within 1 year after primary ovarian cancer surgery: a nationwide cohort study. BMJ Open 2016; 6: $1-7$.

15. Razi S, Ghoncheh M, MohammadianHafshejani A, et al. The incidence and mortality of ovarian cancer and their relationship with the Human Development Index in Asia. Ecancermedicalscience; 10. Epub ahead of print 24 March 2016. DOI: 10.3332/ecancer.2016.628.

16. Ries L. Ovarian cancer. Survival and treatment differences by ag. Cancer 1993; 15: 524-529.

17. Royar J, Becher H, Jenny C-C. Low-Dose Oral Contraceptives: Protective Effect On Ovarian Cancer Risk. 2001; 374: 370-374.

18. Ranjbar R, Nejatollahi F, Sina A, et al. Expression of Vascular Endothelial Growth Factor ( VEGF ) and Epidermal Growth Factor Receptor ( EGFR ) in Patients With Serous Ovarian Carcinoma and Their Clinical Significance. iran J cancer Prev; 8. Epub ahead of print 2015. DOI: 10.17795/ijcp-3428.

19. Salazar-martinez E, Lazcano-ponce EC, Lira-lira GG, et al. Reproductive Factors of Ovarian and Endometrial Cancer Risk in a High Fertility Population in Mexico. cancer Res 1999; 59: 3658-3662.

20. Schietroma C, Ph D, Cianfarani F, et al. Vascular Endothelial Growth Factor-C Expression Correlates with Lymph Node Localization of Human Melanoma Metastases. Cancer 2003; 98: 789-797.

21. Shayan R, Achen MG, Ã SAS. Lymphatic vessels in cancer metastasis: bridging the gaps. Carcinogenesis 2008; 27: 1729-1738.

22. Skirnisdottir I, Seidal T, Akkerud H. The relationship of the angiogenesis regulators VEGF-A, VEGF-R1 and VEGF-R2 to p53 status and prognostic factors in epithelial ovarian carcinoma in FIGO-stages I-II. Int J Oncol 2016; 48: 998-1006.

23. Skobe M, Hawighorst1 T, Jackson DG, et al. Induction of tumor lymphangiogenesis by VEGF-C promotes breast cancer metastasis. Nature; 7.

24. Sturgeon CM, Duffy MJ, Stenman UH, et al. National Academy of Clinical Biochemistry Laboratory Medicine Practice 
Erma Wahyuni et.al. Relationship between plasma vascular endothelial growth factor (VEGF) and ovarian cancer staging.

Guidelines for use of tumor markers in testicular, prostate, colorectal, breast, and ovarian cancers. Clinical Chemistry; 54. Epub ahead of print 1 December 2008. DOI: 10.1373/clinchem.2008.105601.

25. Zheng G, Yu H, Kanerva A, et al. Familial risks of ovarian cancer by age at diagnosis , proband type and histology. plosone 2018; $1-10$.
How to cite this article: Wahyuni E, Hariman H, Edianto D. Relationship between plasma vascular endothelial growth factor (VEGF) and ovarian cancer staging. International Journal of Research and Review. 2021; 8(7): 99-104. DOI: https://doi.org/10.52403/ijrr.20210714 